Hydrol. Earth Syst. Sci., 13, 935-944, 2009

www.hydrol-earth-syst-sci.net/13/935/2009/

(C) Author(s) 2009. This work is distributed under

the Creative Commons Attribution 3.0 License.

\title{
Dye staining and excavation of a lateral preferential flow network
}

\author{
A. E. Anderson ${ }^{1}$, M. Weiler ${ }^{2}$, Y. Alila ${ }^{3}$, and R. O. Hudson ${ }^{3}$ \\ ${ }^{1}$ Sustainable Resource Development, Calgary, Alberta, Canada \\ ${ }^{2}$ Institute of Hydrology, Albert-Ludwigs University, Freiburg, Germany \\ ${ }^{3}$ Department of Forest Resources Management, University of British Columbia Vancouver, British Columbia, Canada \\ Received: 17 March 2008 - Published in Hydrol. Earth Syst. Sci. Discuss.: 15 April 2008 \\ Revised: 5 May 2009 - Accepted: 20 June 2009 - Published: 29 June 2009
}

\begin{abstract}
Preferential flow paths have been found to be important for runoff generation, solute transport, and slope stability in many areas around the world. Although many studies have identified the particular characteristics of individual features and measured the runoff generation and solute transport within hillslopes, very few studies have determined how individual features are hydraulically connected at a hillslope scale. In this study, we used dye staining and excavation to determine the morphology and spatial pattern of a preferential flow network over a large scale $(30 \mathrm{~m})$. We explore the feasibility of extending small-scale dye staining techniques to the hillslope scale. We determine the lateral preferential flow paths that are active during the steady-state flow conditions and their interaction with the surrounding soil matrix. We also calculate the velocities of the flow through each cross-section of the hillslope and compare them to hillslope scale applied tracer measurements. Finally, we investigate the relationship between the contributing area and the characteristics of the preferential flow paths. The experiment revealed that larger contributing areas coincided with highly developed and hydraulically connected preferential flow paths that had flow with little interaction with the surrounding soil matrix. We found evidence of subsurface erosion and deposition of soil and organic material laterally and vertically within the soil. These results are important because they add to the understanding of the runoff generation, solute transport, and slope stability of preferential flow-dominated hillslopes.
\end{abstract}

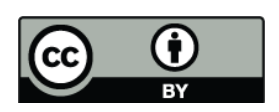

Correspondence to: A. E. Anderson (axel.anderson@gov.ab.ca)

\section{Introduction}

Subsurface flow in hillslopes dominates the hydrological regime, the transport of solutes and nutrients, and can affect slope stability, especially in steep forested watersheds in humid climates. Preferential flow has long been identified as an important factor in these environments (Mosley, 1979). However, the nature of the pathways that water flows through is still largely unknown. Researchers have used dyes and excavation to determine how water exploits vertical and lateral preferential flow paths (e.g. Noguchi et al., 1999; Weiler and Fluhler, 2004). This method involves applying dye solution or paint, either as a line source or by sprinkling, to sections of the soil under steady state conditions. The soil is excavated, photographed, and analysed to determine the flow paths (e.g. Weiler and Fluhler, 2004). These experiments have been used at the smallest scales ( $2 \mathrm{~m}$ or less) and often focus on the vertical movement of water during infiltration. This method is labour intensive and destroys the soil structure, but it has been proven effective. Less destructive methods such as ground penetrating radar, fibre optics, and electrical conductivity have been tested, but they require expensive equipment and have seen limited successes (e.g. Holden et al., 2002; Sherlock and McDonnell, 2003).

The few experiments that use excavation have found that the hillslopes had short (generally less than $5 \mathrm{~m}$ ) preferential flow paths (Noguchi et al., 1999; Terajima et al., 2000). Some steep, forested hillslopes have been reported to have large preferential flow paths, but it was not known how far upslope they extended (Roberge and Plamondon, 1987; Tsukamoto and Ohta, 1988; Kitahara, 1993; Uchida et al., 1999). Even though preferential flow paths are usually short and discontinuous, hillslopes produce fast tracer velocities and rapid subsurface flow responses (Peters et al., 1995; Tani, 1997; Hutchinson and Moore, 2000). These fast velocities

Published by Copernicus Publications on behalf of the European Geosciences Union. 
and subsurface flow responses have led to the idea of a preferential flow network, which describes a series of hydraulically connected preferential flow paths that appear to be physically discontinuous. The exact mechanisms that allow water to exploit these preferential flow pathways are not known, but it is often assumed that increasing soil moisture provides the connection between preferential flow paths (Sidle et al., 2001). Under this assumption, as water is redistributed vertically and laterally the saturated area increases, which increases the number of active preferential flow paths and hence increases the subsurface flow response of the hillslope (Sidle et al., 2000). This dynamic subsurface flow response behaviour has been shown to be influenced by antecedent moisture condition, precipitation intensity and precipitation amount (Tsuboyama et al., 1994; Sidle et al., 1995; Sidle et al., 2000; Uchida et al., 2005; Tromp-van Meerveld and McDonnell, 2006a).

The presence of preferential flow paths is also an important factor in slope stability. Often preferential flow paths are found in landslide scars near the sites where slope failures are initiated (Fannin and Jaakkola, 1999, Uchida et al., 2001). Once the capacity of preferential flow paths is exceeded it is believed that they contribute to high pore water pressures in the surrounding soils, contributing to a high landslide initiation potential (Pierson, 1983). Other studies have shown that they can also rapidly drain soils, thereby decreasing the landslide initiation potential (Pierson, 1983; Fannin et al., 2000). Preferential flow paths are created by the actions of plant roots and burrowing animals. Once formed, subsurface erosion and deposition of material can modify preferential flow paths, altering their capacity to transmit water. Erosion of preferential flow paths is likely to increase their flow capacity, whereas deposition will decrease their capacity, resulting in a potential increase in local pore pressure. Modification of preferential flow paths is affected by soil cohesion (Uchida et al., 1999) and by the volume of water supplied to the features, which is related to the contributing area (Freer et al., 2002). We would expect that higher contributing areas should correspond to preferential flow networks with larger and more connected features especially in concave topography. Most experiments have focused on the individual preferential flow paths and few experiments have examined the connection to physical factors such as the contributing area. Therefore, we have very few general principals that can be used to link preferential flow paths to physical characteristics such as contributing area, slope gradient, or soil types (Sidle et al., 2001).

In this paper, we test the feasibility of extending the smallscale dye staining techniques to the hillslope scale $(30 \mathrm{~m})$. We test the hypotheses that (1) there is a relationship between the contributing area and the extent and connectivity of preferential flow paths, and (2) that there is evidence that preferential flow paths contribute to the subsurface erosion and deposition of material. We also aim to describe lateral preferential flow paths that are active during subsurface flow, their interaction with the surrounding soil matrix, and the velocities of the flow through each cross-section of the hillslope (Sidle et al., 2001)

\section{Methods}

\subsection{Study site}

The experiment was conducted in the Russell Creek research watershed located on north-eastern Vancouver Island, British Columbia, Canada. The watershed ranges in elevation from $275 \mathrm{~m}$ to $1715 \mathrm{~m}$ above sea level (a.s.l.), which places 47 and $52 \%$ of the watershed in the rain-on-snow zone $(300-800 \mathrm{~m})$ and the snow zone (above $800 \mathrm{~m}$ ) respectively. The terrain is steep and the climate is wet. Ten-year average precipitation at two gauges in the watershed was $2258 \mathrm{~mm} / \mathrm{yr}$ (average 1995-2000) at $830 \mathrm{~m}$ a.s.l. and $1906 \mathrm{~mm} / \mathrm{yr}$ (average 1991$2000)$ at $300 \mathrm{~m}$ a.s.l., with the majority of the precipitation falling in the winter months $(80 \%$ of total precipitation in September to April). A $100 \mathrm{~m}$-long hillslope with an average gradient of $30 \%$ was selected for this experiment. The soil characteristics, vegetation, and slope morphology of the site were typical of other sites at Russell Creek. The base of the slope was at $400 \mathrm{~m}$ a.s.l. where rapid subsurface flow had been frequently observed during storms at the road cutbank. The site was part of a larger hillslope that had been intensively instrumented with stream gauges, piezometers and meteorological instrumentation; winter access was relatively easy because the road was in good condition and snowpacks were expected to be transient at the elevation of the site.

The experiment was performed in the lower $30 \mathrm{~m}$ of the hillslope (Fig. 1). The topography of this area was undulating with wet hollows and drier convex ridges. Various contributing areas were identified in relation to the experimental site using surface topography. Soil moisture regimes were mapped out by using plant indicator species. The centre of the lower 10-15 m of the hillslope (Fig. 1) was typical of a topographical hollow with organic and clay-rich soils ( $\mathrm{Ah}$ and $\mathrm{Bg}$ ) less than one metre deep. The remainder of the hillslope (Fig. 1) was convex or planar with podzols that had a $0-10 \mathrm{~cm}$ thick Ae layer, and a Bf layer approximately $1 \mathrm{~m}$ deep. Soils were developed from morainal blanket deposits over compacted glacial till, which formed an impermeable lower bounding layer for the experiment. The hillslope was covered by a 300 -year-old, $200 \mathrm{~cm}$ diameter, $47 \mathrm{~m}$ tall stand of western hemlock (Tsuga heterophylla) and amabilis fir (Abies amabilis).

The topography of Russell Creek watershed is highly variable so it is difficult to determine the frequency, orientation, or the percentage of the watershed covered by hollows and soil types corresponding to those found in the experimental hillslope. However, topographical depressions, hollows, and riparian areas were more typical of the lower, gentler slopes while in the steeper terrain (greater than $30 \%$ slope), 


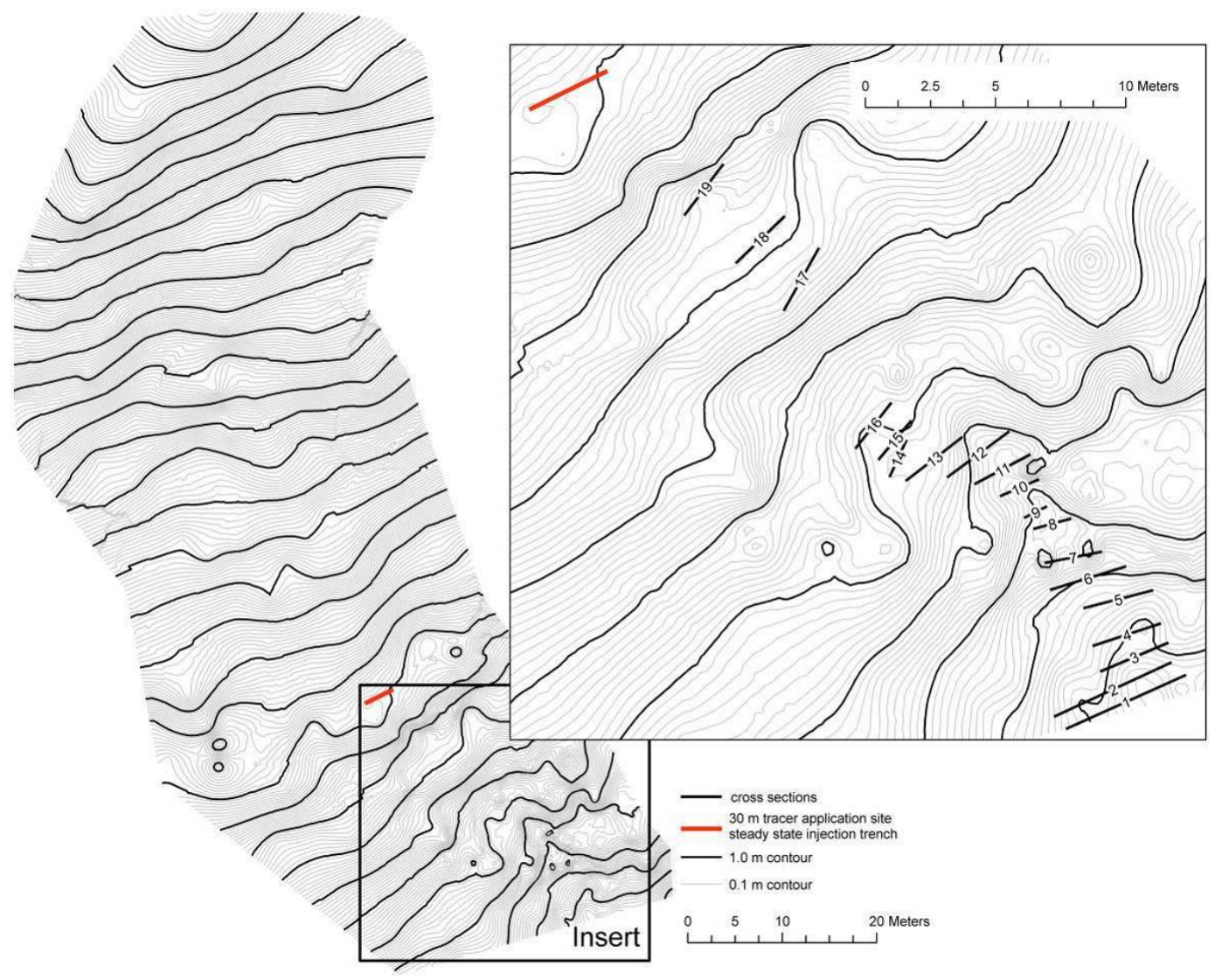

Fig. 1. Contour map of the experimental hillslope showing the location of the dye injection and the photographed cross-sections. This map was developed using the 256 total station survey points for the excavated section and another 262 points for the rest of the hillslope.

the hillslopes were often directly connected to a stream or exposed gully bank without a noticeable hollow or riparian area.

\subsection{Experimental design}

Dyes are commonly used to stain the flow paths used by water during infiltration. Various tracers have been used, including Methylene Blue (Bouma et al., 1977), Acid Red 1 (Ghodrati and Jury, 1990) Brilliant Blue FCF (Flury and Fluhler, 1995; Weiler and Fluhler, 2004) and diluted white paint (Noguchi et al., 1999). We used Brilliant Blue FCF even though the contrast between the dye and the dark soils found at our site was expected to be a problem. Brilliant Blue FCF was chosen because it has a relatively low toxicity, low sorption and high mobility (Flury and Fluhler, 1995). The low sorption and high mobility properties were important because the dye was required to travel $30 \mathrm{~m}$ through the hillslope. The sorption isotherm is also non-linear which creates a sharp boundary at the leading edge of the dye and high contrast to the soil (German-Heins and Flury, 2000). Dyes are usually applied in solution by sprinkling onto the soil; however, in order to delineate the lateral preferential flow paths we created a steady-state flow rate laterally through the hillslope. Steady-state flow was achieved by diverting water at a rate of $23.51 \mathrm{~min}^{-1}$ from a nearby stream into a trench $30 \mathrm{~m}$ above the road cut-bank. The flow rate of $23.51 \mathrm{~min}^{-1}$ was used because it produced similar lateral solute flow rates during tracer experiments conducted under steady-state and natural storm conditions (Anderson et al., 2009). Flow conditions were measured with tipping buckets installed at the road cut-bank and once steady-state flow was achieved, a concentrated solution of Brilliant Blue dye was added to the input trench to create a dye concentration of 4-5 g/l. Dye solution was added for $100 \mathrm{~min}$, which was the approximate time required for peak breakthrough of the applied $\mathrm{NaCl}$ tracer. The input flow of water was then stopped and the hillslope was left to drain overnight $(14 \mathrm{~h})$.

Over the next 4 days, although extremely labour intensive, the hillslope was excavated manually. Machinery would disturb large roots, boulders, and fibrous organic horizons extending upslope, which would damage the upslope soil. Manual excavation also made it possible to prepare each cross-section carefully and to follow the brilliant blue dye upslope between cross-sections to determine the connections between preferential flow features captured in the 


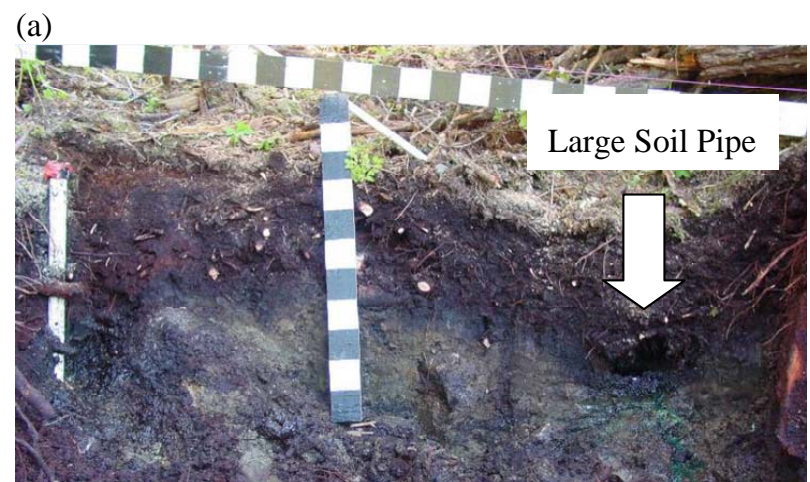

(b)

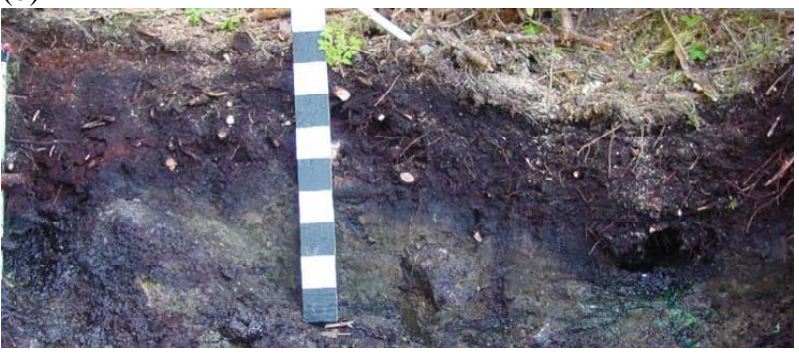

(c)

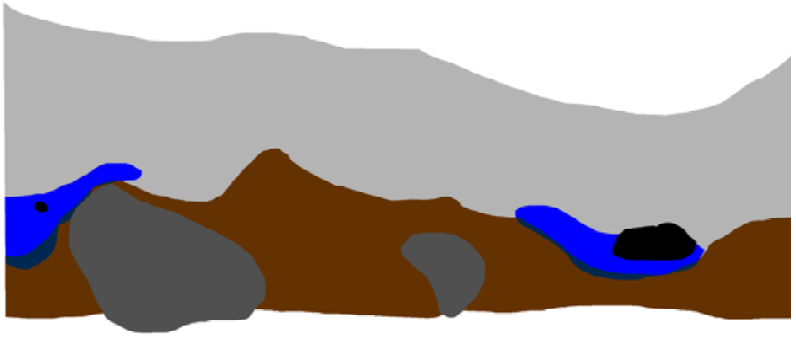

Fig. 2. Cross-section 7, examples of (a) the original photo, (b) the rectified colour corrected image, and (c) the digitized image shown in Fig. 3.

photographed cross-sections. The roots, fallen trees, and boulders made the excavation challenging. To prepare the cross-sections, roots were cut flush with the soil face with reciprocating saws, pruning shears and axes. Wherever possible, boulders were moved carefully; those that were too large to move were left in place. The large fallen trees were cut into disks with a chainsaw and rolled down-slope into the previously excavated sections. Nineteen cross-sections were excavated and prepared for photography. The lower $15-\mathrm{m} \mathrm{sec}-$ tion of the hillslope was progressively excavated and crosssections prepared at 1-m intervals. The one-metre spacing was decided upon after starting the excavation because it was considered adequate to capture the variability among preferential flow paths in this portion of the hillslope. During excavation the stained preferential flow paths and soil were followed continuously up-slope so that connections between the cross sections and the flow paths could be observed. This resulted in 16 cross-sections with observed connections (see Fig. 1 for location of cross-sections). Three additional, one metre-wide trenches were excavated 3-4 m apart in the upper part of the hillslope. These cross-sections were excavated to sample the dye pattern at different contributing areas, but the connections between these cross-sections could not be observed. Each of the cross sections was photographed using a digital camera and surveyed with a Laser Total Station resulting in 256 survey points. The entire $100 \mathrm{~m}$ hillslope was later surveyed with an addition 262 survey points so that contributing areas could be determined more accurately (Fig. 1).

Automated dye pattern analysis was not well suited to analyse the photographs because the dark soils made it impossible for image processing algorithms to distinguish the stained soil from the surrounding matrix (Weiler and Fluhler, 2004). It was also found that the dye could not stain the large voids in the soil, and at this site, there was flow through several large soil pipes $(5-30 \mathrm{~cm}$ diameter). In addition, when some cross-sections were excavated, dyed water drained from the voids and stained soil that had not transmitted water during the application of the tracer. To determine an accurate measure of the stained areas, the images were colour corrected, digitally rectified, and scaled to make one pixel equivalent to one square millimetre (Weiler and Fluhler, 2004). The mineral soil, organic soil, stones, pipes, and stained areas were then manually digitized (see example of the procedure in Fig. 2). Detailed field notes taken during the excavation were used to ensure that all the digitized stained areas correctly represented the observation.

A Digital Elevation Model (0.5 m grid spacing) of the hillslope was derived from the 518 points Total Station survey points (256 from excavated area and 262 points for the rest of the hillslope). A single directional flow algorithm (D8) was used to determine contributing areas for each cross-section based on the surface topography. The local average slope for each cross-section was determined by averaging the pixel slopes for all pixels within $0.5 \mathrm{~m}$ of the cross-sections.

\subsection{Velocity calculations}

We assumed that the total area of the stained soil for each cross-section is equal to the cross sectional area of flow and therefore the Darcy velocity $(V)$ could be calculated for each cross-section by:

$V=\frac{Q}{A}$

where $Q$ was the steady state flow rate and $A$ was the crosssectional stained area including the soil pipes.

\section{Results}

All excavated and analyzed cross-sections shown in Fig. 3 are in the proper $\mathrm{x}$ location with $\mathrm{z}$ location exaggerated so that the observed flow pathways between the cross-sections could be delineated (dashed line). The pathways are not shown in cases where we were unable to follow the flow 


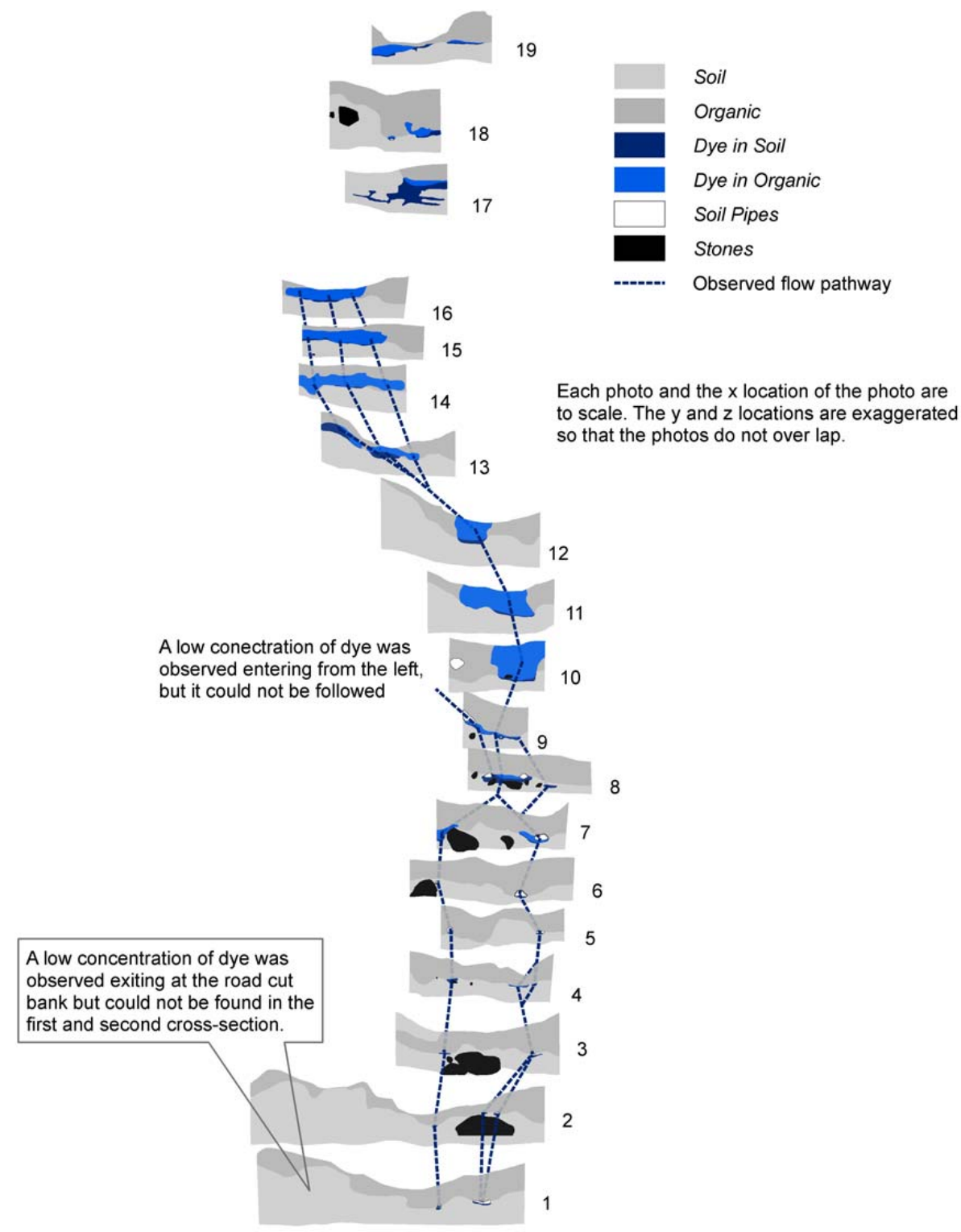

Fig. 3. Cross-sections showing the location of the stained soil, the soil pipes, and the observed flow paths between the cross-sections. The photos and the $\mathrm{x}$ locations are to scale but the $\mathrm{y}$ and $\mathrm{z}$ locations have been exaggerated so that the photos do not overlap.

paths during excavation. The location of each cross section can be seen in Fig. 1. The excavations revealed flow through soil pipes, zones of highly conductive soils, porous organic soils, and the soil matrix. The soils had many live and dead roots in the upper $30-50 \mathrm{~cm}$, but the roots often extended down to the till layer.

Cross-sections 1-9 (Fig. 1) were located in a concave topographical hollow with the largest contributing areas (Table 1), where we observed the largest, most developed preferential flow pathways. The centre portion of the cross-sections contained a hydraulically connected set of preferential flow paths. The dye solution moved almost exclusively through the preferential flow paths, interacting only minimally with the surrounding soils. These flow paths included large soil pipes up to $40 \mathrm{~cm}$ in diameter and areas of fine gravels (particle size $2-5 \mathrm{~mm}$ ) usually above the till layer (as represented by cross-section 9) or in-filled into what appeared to be soil pipes (as represented by cross-section 4). Most of the material on the bottom of the soil pipes was also fine gravel. The soil surrounding this portion of the network was shallow (less than $1 \mathrm{~m})$ with a clay-rich mineral horizon $(\mathrm{Bg})$ and a deep Ah horizon of well decomposed organic material. In this portion of the network we calculated velocities (using Eq. 1) that were one and two orders of magnitude higher than those at the other cross-sections (Table 1). The velocity in crosssections with soil pipes (1-3 and 5-9) is underestimated. We 
Table 1. The area of stained soil, pipe cross-sectional area, velocity of the flow through each cross-section.

\begin{tabular}{|c|c|c|c|c|c|c|}
\hline \multirow[b]{2}{*}{ Cross-section } & \multicolumn{3}{|c|}{ Area of staining } & \multirow[b]{2}{*}{$\begin{array}{r}\text { Darcy } \\
\text { velocity } \\
\mathrm{m} \mathrm{hr}^{-1}\end{array}$} & \multirow[b]{2}{*}{$\begin{array}{r}\text { Local } \\
\text { Slope } \\
\%\end{array}$} & \multirow[b]{2}{*}{$\begin{array}{r}\text { Contributing } \\
\text { area } \\
\mathrm{m}^{2}\end{array}$} \\
\hline & $\begin{array}{r}\text { Mineral } \\
\text { soil } \\
\mathrm{cm}^{2}\end{array}$ & $\begin{array}{r}\text { Organic } \\
\text { Soil } \\
\mathrm{cm}^{2}\end{array}$ & $\begin{array}{r}\text { Large } \\
\text { Pipes } \\
\mathrm{cm}^{2}\end{array}$ & & & \\
\hline 1 & $\mathrm{~b}$ & & 195 & 72.1 & 13.3 & 1645 \\
\hline 2 & $\mathrm{~b}$ & & 100 & 140.9 & 20.3 & 1629 \\
\hline 3 & b & & 107 & 131.1 & 20.4 & 1604 \\
\hline 4 & 184 & 59 & 0 & 58.0 & 18.7 & 1591 \\
\hline 5 & 21 & 28 & 163 & 66.5 & 23.8 & 1591 \\
\hline 6 & $\mathrm{~b}$ & & 223 & 63.1 & 33.7 & 1589 \\
\hline 7 & $\mathrm{~b}$ & & 300 & 47.0 & 36.4 & 1588 \\
\hline 8 & 758 & 289 & 214 & 11.2 & 12.5 & 1581 \\
\hline 9 & 296 & 442 & 330 & 13.2 & 21.9 & 1577 \\
\hline 10 & 238 & 5628 & 0 & 2.4 & 40.5 & 1557 \\
\hline 11 & 228 & 5254 & 0 & 2.6 & 19.6 & 1197 \\
\hline 12 & 318 & 2205 & 0 & 5.6 & 28.4 & 1177 \\
\hline 13 & 1274 & 1533 & 0 & 5.0 & 16.3 & 356 \\
\hline 14 & 78 & 4226 & 0 & 3.3 & 8.3 & 350 \\
\hline 15 & 214 & 3228 & 0 & 4.1 & 11.7 & 343 \\
\hline 16 & 183 & 2740 & 0 & 4.8 & 15.8 & 156 \\
\hline 17 & 2883 & 615 & 0 & 4.0 & 19.2 & 126 \\
\hline 18 & 249 & 722 & 23 & 14.2 & 7.7 & 124 \\
\hline 19 & 390 & 1276 & 0 & 8.5 & 28.9 & 79 \\
\hline
\end{tabular}

a Darcy velocity for the cross-sections with stained soil was as; $V=Q / A_{s}$, where $A_{s}$ is the stained area plus the area of the pipes, where applicable.

${ }^{\mathrm{b}}$ Staining around pipes was not presumed to be from matrix flow, but from water transferred from the soil pipes.

assumed that the soil pipes were completely filled with water during the experiment, while there is evidence to suggest that the pipes were only partially filled; this was clearly seen in many larger pipes where only the lower half of the inside pipe wall was stained.

Cross-sections 10-13 had vertical bands of dye within a relatively deep $(30-50 \mathrm{~cm})$, homogenous, fibrous organic soil horizon that was poorly decomposed and contained many tree and shrub roots. This dye pattern could be a result of flow connecting the upper cross-section 14 to the preferential flow pathway (area of fine gravel) located below the organic horizon in cross-sections $10-13$. On the other hand, in cross-sections 14-16 the dye solution was distributed horizontally in the same type of organic horizon. This horizontal distribution of dye could indicate that the flow of water used the organic soils preferentially due to their higher hydraulic conductivity than the surrounding mineral soil and till. This area of hillslope had relatively flat topography as indicated by the local slopes (Table 1) with no large preferential flow paths. These organic soils were dark, which made it difficult to see the flow paths. Cross-section 10 had a large preferential pathway (large soil pipe) in left portion of the crosssection; however this pathway contained clear water without any dye solution.
Dye solution was found exiting the profile on the left of cross-section 1 and entering the profile from the left of crosssection 9 by way of flow paths that could not be followed. While we believe that we excavated all of the dyed soil from cross-sections 1 through 16 , it is possible that we missed some in cross-sections 17-19. The preferential pathways were not followed above cross-section 16 so the linkages between cross-sections 17 to 19 are not known. Consequently, the dye pattern presented for cross-sections 17-19 may not include all the pathways used to transmit water from the trench. It is likely that the low concentration of dye found entering cross-section 9 from the left and exiting to the left of cross-section 1 came from additional flow paths to the left of the profile, but due to the low concentration and to the appearance of clear water from a soil pipe on the left side of cross-section 10, there is clearly some interference due to additional flow paths from other parts of the hillslope on the left side of our profile. These disconnections in the network presented in Fig. 3 illustrate two limitations of this method of dye staining and excavation using brilliant blue dye. First, the brilliant blue dye is difficult to find and distinguish the individual flow pathways in the dark organic and clay-rich soils. This is especially true for the automated computer algorithms that could be used to identify the dye concentration 
and yield additional data. Also, only observed connections are displayed in the Fig. 3, so cross-sections without observed connections only sample the network of preferential pathways and do not show how they connect to create a complete network. Despite these limitations, the method produced an accurate description of $16 \mathrm{~m}$ of a hillslope preferential flow network with three additional soil cross-sections that sample flow pathways exploited in the same network with different slopes and contributing areas.

The stained area in cross-section 17 showed flow through the organic layer and through underlying layers of coarser mineral soil. Cross-section 18 had flow through organic soil and a Bf horizon. Within the horizon of lower conductivity, a 6-cm diameter soil pipe was discovered in the lower centre of cross-section 18 (Fig. 3). In section 19 the soil in the centre of the cross-section was very shallow because a windthrown tree had removed a large part of the mineral soil. The flow through this cross-section followed the subsurface topography and was confined to the organic and mineral soils above the till.

When cross-section 18 was excavated, the soil pipe was severed and dye solution poured out under pressure. This soil pipe was circular in cross-section, suggesting that it was initially formed by a tree root. The bottom and sides of this pipe were lined with gravel of approximately $2 \mathrm{~mm}$ mean diameter (evidence of past erosion), and the pipe was completely filled with fine organic material. Dye solution was also found around a dead root in the right-hand portion of the cross-section 18 (right upper stained area in cross-section 18). However, unlike the other pipe low in the profile, the staining was limited to the lower half of the root, which suggested that only part of the void around the root contributed to lateral flow.

\subsection{Transport of soil and organic material}

We speculate that fine clay and organic material were leached and transported from the upper slope and from local convex slope sections to the hollows where they accumulated. Evidence of buried organic material within this brown mineral soil type suggested that there was preferential transport of water and fine material to depth within the soil, which accumulated in areas with preferential flow paths (old and new). The lateral and vertical redistribution of fine organic material was also evident in cross-sections 1, 2, 17, and 18. At the road cut-bank, a low concentration of dye solution drained from the soil face (left side of cross-sections 1 and 2 in Fig. 3). Cross-sections 1 and 2 had buried dark soil that could have been preferential flow paths filled with accumulated organic material. Although no dye solution was found within the soil, a weak dye solution was observed exiting the soil at the road cut-bank. These dark soils were connected to the same preferential flow paths that showed strong response during natural events and the steady state experiments. Cross-section 17 had similar redistribution of organic material into the mineral soil.

\section{Discussion}

\subsection{Modification of preferential flow paths}

The observations at this hillslope show that there appears to be a link between the contributing area and the distribution of preferential flow paths. This experiment showed the presence of highly developed preferential flow paths corresponding to the largest contributing areas (greater than $1100 \mathrm{~m}^{2}$ ). These areas also had the largest percentage of hillslope outflow during rainfall events and for steady state experiments (Anderson et al., 2009). Small contributing areas (less than $400 \mathrm{~m}^{2}$ ) and relatively flat local topography (less than 15\%) coincided with areas that had few preferential flow pathways. This suggests that a soil with a small contributing area might not receive flow rates large enough to modify and maintain large preferential flow paths. On the other hand the soils in the hollow are different than soils elsewhere in the hillslope, since they have a higher clay and organic content. This might help to maintain large preferential features since clayrich soils have greater cohesion than sandy soils (Jones et al., 1997; Tsukamoto, 1997). We speculated that the topographic hollow is richer in clay than soils elsewhere because water transported the clay into the hollow. While it is possible that the clay was formed in situ by incongruent dissolution of primary minerals, there was evidence that organic material was transported into the soil, thus it is likely that clay was deposited by the same mechanism. Note that there is a highly non-linear relation between contributing area and flow velocity, both of which increase rapidly below section 10 as stained area decreases. This transition corresponds to the change in soil type from hillslope podzols to the organic and clay-rich soils in the topographic hollow. Preferential flow is known to converge into hollows and the acceleration at the point of convergence causes erosion of fine material, which tends to keep the flow path open. Either way, the reason for the highly developed preferential flow network is due to concentrated inflows into the hollow.

It is recognized that subsurface erosion contributes to stream sediment (Onda, 1994; Terajima et al., 1997). This subsurface erosion is thought to be important for the modification and maintenance of preferential flow paths (Uchida et al., 1999). In steep forested headwater catchments, direct connectivity of hillslopes to stream channels often facilitates the subsurface transport of sediments directly into streams. However, without an "exit" for the sediments, such as a road cut or stream bank, sediment is likely to accumulate in soil pipes as found in most of our excavated cross-sections. This means that the processes that maintain the preferential flow network also have the ability to fill in some features, resulting in lower capacity and flow rate. As features in the 
preferential network are filled in, water is forced into other preferential flow paths, causing the network to change over time (Sidle et al., 2001). This subsurface erosion and deposition could affect the soil development and help contribute to the varying soil types found in this watershed. The soils with small contributing areas contribute fine material to soils with larger contributing areas. The soil cross-sections excavated during this experiment were classified into two groups in the results section; those that receive large amounts of water, sediments, and organic material (cross-sections 1-13) and those that lose sediments and organics (cross-sections 1419).

Preferential transport of fine material was evident within cross-sections as well. For example, there was evidence of erosion and deposition in the soil pipe in the lower centre part of cross-section 18 (Fig. 3). There was fine gravel on the bottom of the feature, indicating that it was connected to an outlet that allowed for the erosion of finer sediments, leaving the gravel behind. However, the pipe was filled with fine organic material suggesting that at some point in time the outlet ceased to function, allowing the organics to accumulate. Despite being filled with fine material, the pipe held water that poured out under pressure when the cross-section was excavated. It extended up-slope and held a volume of dyed water that produced a pressure head even 4 days after the steady state experiment was initiated. For the water to enter the feature, it had to displace water that was already in the pipe before dye solution was added to the input trench. Presumably, the dyed solution entered the pipe when the pore pressure was higher and water was displaced out of the feature down-slope of section 18. The fact that it was filled with fine organics supports the hypothesis that the pipe was temporarily blocked. On the other hand, the pattern of high pore water pressure due to pipe network activation followed by a slow decline once the network disconnected supports an alternative hypothesis that the feature was a dead-end pipe. As described by Sidle (1984) and Brand et al. (1986) dead-end pipes cause a rapid rise in pore water pressure in the surrounding soil as the void in the pipe is filled, followed by a slow decline as the water is drained via matrix flow. This amounts to a question of whether the feature is transient or permanent, which makes little difference from the perspective of modeling preferential flow at the hillslope scale. Our research provides a one-time snapshot of a dynamic network and we assume that at a different time we would have observed different linkages.

\subsection{Conceptual models of runoff}

The general conceptual model of lateral preferential flow networks relies on the increase in soil wetness. As the soil wetness increases, there is an increase in the connections in the preferential flow network, causing faster subsurface velocities and increasing the area of hillslope contributing to runoff (Tsuboyama et al., 1994; Sidle et al., 2000; Uchida et al.,
2005; Tromp-van Meerveld and McDonnell, 2006b). These excavations support this conceptual model. We observed that the preferential flow paths were connected by matrix flow through mineral and organic soils. In some areas, this saturated flow was perched above soil with low hydraulic conductivity and spread out horizontally in the overlying layers of more conductive soils. In other areas the flow had vertical components because the water was flowing downward to areas with higher conductivities. These observations showed that a connection may be established by increased soil wetness within a small localized area.

The subsurface flow in this hillslope is highly dynamic and depends on the precipitation characteristics and antecedent condition. Trenched hillslopes from around the world have identified differences in subsurface flow characteristics based on the subsurface topography and the saturated zone connections of the hillslope and the trench (e.g. Tani, 1997; Hutchinson and Moore, 2000; Freer et al., 2002; Trompvan Meerveld and McDonnell, 2006a). The excavations presented here show that trenches with large contributing areas collect flow from preferential flow networks that are efficient at transferring water, due in part to a high degree of hydraulic connectivity. The soils in these areas could transport water one order of magnitude faster than other soils (Anderson et al., 2009). The dye staining also revealed that there is often little interaction between water in the preferential flow path and the surrounding soil matrix unless there was a constriction in the preferential flow network. This is important for understanding the transport and dilution of solutes and pollutants. Solutes deposited in soils with larger contributing areas (hence a well established preferential flow network) are likely to have quicker travel times and minimal interaction with the water in the soil matrix, compared to solutes deposited in soils with smaller contributing areas, which are likely to travel further at slower speeds and have more interaction with water in the soil matrix (pre-event water). This may result in more dilution and retardation of the solute in soils with small contributing areas relative to those with large contributing areas.

\subsection{Landslide hazard}

Landslide activity and debris flows are common at Russell Creek and surrounding areas (Fannin and Wise, 2001; Nistor and Church, 2005). Areas with similar topography, climate, and soil types as this watershed are also prone to landslides. Preferential flow paths are sometimes found near landslide initiation points (Fannin and Jaakkola, 1999; Uchida et al., 2001). The water table depth and the proximity to preferential flow paths influence the pore water pressure in preferential flow dominated hillslopes. Preferential flow paths can rapidly drain the soil water, reducing the water table and the pore water pressure (Montgomery and Dietrich, 1994 and 1995; Sidle, 1986; Fannin et al., 2000). However, when preferential flow paths reach their capacity, are in-filled 
by subsurface deposition, or are damaged, preferential flow could increase the landslide hazard by increasing pore water pressure in the surrounding soils (Uchida et al., 2001). The preferential flow paths found in cross-section 18 and discussed in Sect. 4.1 exemplify this phenomenon. During subsurface flow conditions, this increase in pore water pressure could increase the landslide initiation hazard. On the other hand, the subsurface flow that stained the lower half of the dead root in the right side of cross-section 18 (Fig. 3) had completely drained and the only evidence of flow was dye on the root and surrounding soils. This means that this feature was hydraulically connected to lower slope sections and could drain even under low pore water pressures. At the flow rate used for the experiment, this feature would likely decrease the landslide initiation hazard because it would reduce the local water table.

Soils with large contributing areas are often the initiation sites of landslides, which can be attributed to accumulation of subsurface water. However, it could also in part be due to the linkage between large contributing areas and highly developed and hydraulically connected preferential flow paths. If the preferential flow paths observed in the hollow were dead-ended, blocked or their capacity was reached, there is a high probability that pore water pressure would increase in the surrounding soils. If there were no other preferential flow paths transmitting the water, the likely outcomes would be (1) discharge of water to surface runoff, or (2) if the conditions are right, the initiation of a slope failure. The relationship between the contributing area, subsurface storm water volume, and the modification and maintenance of preferential flow paths could be used to enhance the prediction of areas with high landslide initiation hazard (e.g. Wu and Sidle, 1995). Nevertheless, we need more larger-scale excavation experiments to better develop the relationship between topographic units and preferential flow paths in steep forested hillslopes.

\section{Summary and conclusions}

We stained a $30 \mathrm{~m}$ section of hillslope with a food dye under steady-state conditions and then excavated the hillslope to discover the lateral preferential flow paths, the connections between the features, and velocities through each crosssection. At this site, the material that connected the preferential flow paths was important for controlling the hillslope velocity, and the dye patterns suggested that saturated flow through permeable soil provided connection between the individual preferential flow paths. Observations of erosion and deposition of fine soil and organic material within the preferential flow paths suggested that preferential flow influenced the redistribution of the fine soil and organic material within the hillslope. Some preferential flow paths were only partially filled with water, and others were under pressure. We tested the hypothesis that the preferential flow network was linked to the contributing area. The excavations revealed that the soils with the largest contributing area derived from the concave surface topography contained the largest and most connected features. These large features (up to $30 \mathrm{~cm}$ in diameter and meters in length) transport water and solutes while interacting minimally with the surrounding soil matrix. These findings have implications for subsurface flow generation, soil development, solute transport, and slope stability and could be used to develop better predictions of lateral preferential subsurface flow.

Acknowledgements. We would like to acknowledge Markus Hrachowitz, Georg Jost, Jeff McDonnell, and Pascal Szeftel for assisting with the excavation. The efforts of two anonymous reviewers are appreciated. The British Columbia Forest Investment Account Forest Science Program and the Natural Sciences and Engineering Research Council of Canada provided funding for this project.

Edited by: K. Bishop

\section{References}

Anderson, A. E., Weiler, M., Alila, Y., and Hudson, R. O.: Subsurface flow velocities in a hillslope with lateral preferential flow, Water Resour. Res., in review, 2009.

Bouma, J., Jongerius, A., Boersma, O., Jager, A., and Schoonderbeek, D.: Function of Different Types of Macropores During Saturated Flow through 4 Swelling Soil Horizons, Soil Sci. Soc. Am. J., 41(5), 945-950, 1977.

Brand, E. W., Dale, M. J., and Nash, J. M.: Technical Note: Soil pipes and slope stability in Hong Kong, Q. J. Eng. Geol., 19, 301-303, 1986.

Fannin, R. J. and Jaakkola, J.: Hydrological response of hillslope soils above a debris-slide headscarp, Can. Geotech. J., 36(6), 1111-1122, 1999.

Fannin, R. J., Jaakkola, J., Wilkinson, J. M. T., and Hetherington, E. D.: Hydrologic response of soils to precipitation at Carnation Creek, British Columbia, Canada, Water Resour. Res., 36(6), 1481-1494, 2000.

Fannin, R. J. and Wise, M. P.: An empirical-statistical model for debris flow travel distance, Can. Geotech. J., 38(5), 982-994, 2001.

Freer, J., McDonnell, J. J., Beven, K., Peters, N. E., Burns, D. A., Hooper, R. P., Aulenbach, B., and Kendall, C.: The role of bedrock topography on subsurface storm flow, Water Resour. Res., 38(12), 1269, doi:101029/2001WR000872, 2002.

Flury, M. and Fluhler, H.: Tracer Characteristics of Brilliant Blue Fcf, Soil Sci. Soc. Am. J., 59(1), 22-27, 1995.

German-Heins, J. and Flury, M.: Sorption of Brilliant Blue FCF in soils as affected by $\mathrm{pH}$ and ionic strength, Geoderma, 97(1-2), 87-101, 2000.

Ghodrati, M. and Jury, W. A.: A Field-Study Using Dyes to Characterize Preferential Flow of Water, Soil Sci. Soc. Am. J., 54(6), 1558-1563, 1990.

Holden, J., Burt, T. P., and Vilas, M.: Application of groundpenetrating radar to the identification of subsurface piping in blanket peat, Earth Surf. Proc. Land., 27(3), 235-249, 2002. 
Hutchinson, D. G. and Moore, R. D.: Throughflow variability on a forested hillslope underlain by compacted glacial till, Hydrol. Process., 14(10), 1751-1766, 2000.

Jones, J. A. A., Richardson J. M. and Jacob, H. J.: Factors controlling the distribution of piping in Britain: a reconnaissance, Geomorphology, 20, 289-306, 1997.

Kitahara, H.: Characteristics of pipe flow in forested slopes, IAHSAISH P., 212, 235-242, 1993.

McDonnell, J. J.: A Rationale for Old Water Discharge through Macropores in a Steep, Humid Catchment, Water Resour. Res., 26(11), 2821-2832, 1990.

Montgomery, D. R. and Dietrich, W. E.: A physically based model for the topographic control on shallow landsliding, Water Resour. Res., 30(4), 1153-1171, 1994.

Montgomery, D. R., and Dietrich, W. E.: Hydrologic processes in a low-gradient source area, Water Resour. Res., 31(1), 1-10, 1995.

Mosley, M. P.: Streamflow Generation in a Forested Watershed, New-Zealand, Water Resour. Res., 15(4), 795-806, 1979.

Nistor, C. J. and Church, M.: Suspended sediment transport regime in a debris-flow gully on Vancouver Island, British Columbia, Hydrol. Process., 19(4), 861-885, 2005.

Noguchi, S., Tsuboyama, Y., Sidle, R. C. and Hosoda, I.: Morphological characteristics of macropores and the distribution of preferential flow pathways in a forested slope segment, Soil Sci. Soc. Am. J., 63(5), 1413-1423, 1999.

Onda, Y.: Seepage Erosion and Its Implication to the Formation of Amphitheater Valley Heads - a Case-Study at Obara, Japan. Earth Surf. Proc. Land., 19(7), 627-640, 1994.

Peters, D. L., Buttle, J. M., Taylor, C. H. and Lazerte, B. D.: Runoff Production in a Forested, Shallow Soil, Canadian Shield Basin, Water Resour. Res., 31(5), 1291-1304, 1995.

Pierson, T. C.: Soil pipes and slope stability, Q. J. Eng. Geol., 16, 1-11, 1983.

Roberge, J. and Plamondon, A. P.: Snowmelt runoff pathways in a boreal forest hillslope, the role of pipe throughflow, J. Hydrol., 95, 39-54, 1987.

Sherlock, M. D. and McDonnell, J. J.: A new tool for hillslope hydrologists: spatially distributed groundwater level soilwater content measured using electromagnetic induction, Hydrol. Process., 17(10), 1965-1977, 2003.

Sidle, R. C.: Shallow groundwater fluctuations in unstable hillslopes coastal Alaska, Zeitschrift für Gletscherkunde und Glazialgeologie, 20, 79-95, 1984.

Sidle, R.C.: Groundwater accretion in unstable hillslopes of coastal Alaska, IAHS-AISH P., 156, 335-343, 1986.

Sidle, R. C., Noguchi, S., Tsuboyama, Y., and Laursen, K.: A conceptual model of preferential flow systems in forested hillslopes: evidence of self-organization, Hydrol. Process., 15(10), 16751692, 2001.

Sidle, R. C., Tsuboyama, Y., Noguchi, S., Hosoda, I., Fujidea, M., and Shimizu, T.: Seasonal Hydrologic Response at Various Spatial Scales in a Small Forested Catchment, Hitachi-Ohta, Japan, J. Hydrol., 168(1-4), 227-250, 1995.
Sidle, R. C., Tsuboyama, Y., Noguchi, S., Hosoda, I., Fujidea, M., and Shimizu, T.: Stormflow generation in steep forested headwaters: a linked hydrogeomorphic paradigm. Hydrol. Process., 14(3), 369-385, 2000.

Tani, M.: Runoff generation processes estimated from hydrological observations on a steep forested hillslope with a thin soil layer, J. Hydrol., 200(1-4), 84-109, 1997

Terajima, T., Sakamoto, T., Nakai, Y., and Kitamura, K.: Suspended sediment discharge in subsurface flow from the head hollow of a small forested watershed, northern Japan, Earth Surf. Proc. Land., 22(11), 987-1000, 1997.

Terajima, T., Sakamoto, T. and Shirai, T.: Morphology, structure and flow phases in soil pipes developing in forested hillslopes underlain by a Quaternary sand-gravel formation, Hokkaido, northern main island in Japan, Hydrol. Process., 14(4), 713-726, 2000.

Tromp-van Meerveld, H. J. and McDonnell, J. J.: Threshold relations in subsurface stormflow: 1. A 147-storm analysis of the Panola hillslope, Water Resour. Res., 42(2), W02410, doi:10.1029/2004WR003778, 2006a.

Tromp-van Meerveld, H. J. and McDonnell, J. J.: Threshold relations in subsurface stormflow: 2. The fill and spill hypothesis, Water Resour. Res., 42(2), W02411, doi:10.1029/2004WR003800, 2006b.

Tsuboyama, Y., Sidle, R. C., Noguchi, S. and Hosoda, I.: Flow and Solute Transport through the Soil Matrix and Macropores of a Hillslope Segment, Water Resour. Res., 30(4), 879-890, 1994.

Tsukamoto, Y. and Ohta, T.: Runoff Process on a Steep Forested Slope, J. Hydrol., 102(1-4), 165-178, 1988.

Uchida, T., Kosugi, K., and Mizuyama, T.: Effects of pipeflow on hydrological process and its relation to landslide: a review of pipeflow studies in forested headwater catchments, Hydrol. Process. 15, 2151-2174, 2001.

Uchida, T.: Clarifying the role of pipe flow on shallow landslide initiation, Hydrol. Process., 18(2), 375-378, 2004.

Uchida, T., Kosugi, K., and Mizuyama, T.: Runoff characteristics of pipeflow and effects of pipeflow on rainfall-runoff phenomena in a mountainous watershed, J. Hydrol., 222(1-4), 18-36, 1999.

Uchida, T., Kosugi, K., and Mizuyama, T.: Effects of pipeflow on hydrological process and its relation to landslide: a review of pipeflow studies in forested headwater catchments, Hydrol. Process., 15(11), 2151-2174, 2001.

Uchida, T., Meerveld, I. T., and McDonnell, J. J.: The role of lateral pipe flow in hillslope runoff response: an intercomparison of non-linear hillslope response, J. Hydrol., 311(1-4), 117-133, 2005.

Weiler, M. and Fluhler, H.: Inferring flow types from dye patterns in macroporous soils, Geoderma, 120(1-2), 137-153, 2004.

Wu, W. and Sidle, R. C.: A distributed slope stability model for steep forested basins, Water Resour. Res., 31(8), 2097-2110, 1995. 